\title{
Systematic Reviews and Quality Appraisal of In Vitro Cancer Studies: Investigation of Current Practice
}

\author{
MIKE BRACHER ${ }^{1}$, GEOFFREY J. PILKINGTON ${ }^{2}$ and KAREN PILKINGTON ${ }^{3}$ \\ ${ }^{1}$ School of Health Sciences, University of Southampton, Southampton, U.K.; \\ ${ }^{2}$ School of Pharmacy and Biomedical Sciences, University of Portsmouth, Portsmouth, U.K.; \\ ${ }^{3}$ School of Health and Care Professions, University of Portsmouth, Portsmouth, U.K.
}

\begin{abstract}
Background/Aim: To assess the quantity and quality of systematic reviews of in vitro cancer studies. Materials and Methods: PubMed, MEDLINE, Embase, Web of Knowledge and PROSPERO databases were searched. Articles described as systematic reviews of in vitro studies, focused on or relevant to cancer and published in English were selected and appraised using an adapted version of AMSTAR 2 'critical domains'. Results: From 4,021 records, 41 reviews described as systematic and cancer-related were identified. Publication dates indicate increasing frequency of systematic review conduct. Mean number of databases searched was three (range $=1-8)$. Thirty-six reviews $(88 \%)$ reported search methods, 35 (85\%) specified inclusion criteria, 26 (63\%) reported study selection methods, and 21 (51\%) used reporting guidelines. Only 13 reviews (32\%) involved formal quality assessment. Conclusion: Detailed investigation of reviews of cancer-relevant in vitro studies indicates need for further development and use of robust search strategies, appropriate quality assessment tools, and researchers with relevant skills.
\end{abstract}

Systematic methods for collating research have been used to answer specific questions since James Lind published A Treatise on the Scurvy in 1753 (1). The rise of clinical epidemiology and evidence based medicine have encouraged and necessitated the application of research results into clinical practice, with Archie

This article is freely accessible online.

Correspondence to: Karen Pilkington, School of Health and Care Professions, University of Portsmouth, University of Portsmouth, James Watson West, 2 King Richard $1^{\text {st }}$ Road, Portsmouth, U.K. Tel: +44 02392842994, e-mail: karen.pilkington@port.ac.uk

Key Words: Neoplasms, systematic reviews, critical appraisal, in vitro studies, in vitro techniques, cell culture, quality, review.
Cochrane's seminal text Effectiveness and Efficiency (1972) having made a significant impact (2). To ensure practice based on 'best evidence', research was to be identified, selected and assessed using systematic methods that were transparent, objective and reproducible. The first set of systematic reviews focused on pregnancy and childbirth but the scope quickly expanded to include a wide range of health interventions. In most cases, systematic reviews collate, analyse and synthesise (either narratively or statistically, as in meta-analysis) the results of randomised controlled trials (RCTs) (3). The results of a series of RCTs that individually may not have provided conclusive results on whether particular interventions were effective could, when combined, achieve clear answers to such questions.

Alongside the increasing scope of systematic reviews (and meta-analyses), there has been a considerable development in techniques and tools to support their conduct. Thus, reporting tools such as PRISMA (Preferred Reporting Items for Systematic Reviews and Meta-Analyses) (4) were developed and are now widely used, while training programmes, checklists and criteria exist to support health professionals in reading and appraising research (5). Together with these initiatives, developments have taken place in statistical techniques to enable increasingly sophisticated approaches to combining the results of different trials (6).

While far less extensive than the developments in clinical/human research, similar initiatives have been established in other fields of research. In animal research, the CAMARADES initiative (Collaborative Approach to MetaAnalysis and Review of Animal Data from Experimental Studies) has facilitated international, collaborative approaches to collating data and a supportive framework for groups involved in such work (7). Reporting guidelines for in vivo studies have also been published (8) in toxicology, and the Evidence Based Toxicology Collaboration is currently undertaking a number of projects including advocating use of systematic methods in conducting chemical risk assessments (9). 
Table I. Search strategies for each database.

\begin{tabular}{ll}
\hline Database & Search terms and limits \\
\hline MEDLINE & (TI systematic review) AND (MH In vitro Techniques OR TI In vitro) \\
PubMed & [("Neoplasms"[Mesh] or cancer or tumor or tumour)) AND ((("In vitro \\
& Techniques"[Mesh]) OR "in vitro"[Title/Abstract]) AND systematic[sb]) \\
Embase & ((systematic review).m_titl.) AND in vitro study/ \\
$\begin{array}{l}\text { Web of Knowledge } \\
\text { (Databases: WOS, BIOSIS, KJD, RSCI, SciELO). }\end{array}$ & TITLE: (in vitro) AND TITLE: (systematic review) AND TOPIC: (cancer) \\
PROSPERO & Vitro (limited to Health Area: cancer) \\
\hline
\end{tabular}

KJD: Korean Journal Database; MeSH/MH: medical subject heading; RSCI: Russian Science Citation Index; sb: subset; SciELO: Scientific Electronic Library Online; TI: title; WOS: World of Science.

It has previously been claimed that adherence to reporting guidelines in systematic reviews of in vitro studies is generally poor (10). Reporting assessed against the PRISMA tool resulted in a mean overall quality score of reported items of $68 \%$. The authors scored the papers on whether or not specific items in the PRISMA checklist were reported but not on precisely what methods were used (i.e., they assessed whether databases and quality criteria were reported but not which criteria were used or which databases were searched). While criteria for assessment of the quality of studies is crucial for unbiased, reliable reviews of the research literature, assessment of relevance of the technique or method employed is also a key element. Increasing numbers of systematic reviews of in vitro studies over the previous 10 years were noted but reporting did not appear to improve over this period.

While these findings are important to the field, only systematic reviews published up to 2016 were included. In addition, a wide range of research areas was covered by the included systematic reviews, with at least $50 \%$ relating to dental or orthodontic research. There exists a need for detailed investigation of contemporary use of the systematic review approach in the cancer field due to specific challenges in representing cancer in in vitro models and in conducting human relevant in vitro cancer research. The current investigation addresses this gap. It is also crucial that systematic reviews are conducted effectively and appropriately to the field to reveal unnecessary replication and/or poor research in the field so that optimal use is made of future resources.

This review uses systematic methods to analyse the prevalence, focus, and methods used in publications presented as systematic reviews of in vitro studies in cancer or of particular relevance to the cancer field.

\section{Materials and Methods}

The current investigation involved a systematic analysis of current practice in reporting, evidence identification, and quality assessment in systematic reviews of in vitro studies relating to cancer.
Search and screening methods. Searches were carried out for systematic reviews involving in vitro methods in the field of cancer or with relevance to cancer. Databases searched included PubMed, MEDLINE, Embase, Web of Knowledge, and the PROSPERO International Prospective Register of Systematic Reviews. Searches were conducted between April and July 2018 and updated in December 2019. PubMed, MEDLINE and Embase were searched again in April 2021. Search terms are shown in Table I. Search results were downloaded into Excel and Abstrackr. Resulting titles and abstracts were screened for relevant articles with reference to inclusion/exclusion criteria. Screening of all records was conducted by at least two of three reviewers (KP, MB, and GP) working independently, with disagreements resolved through discussion or by consultation with a third reviewer. All study titles were screened for potential relevance to cancer research and potentially relevant articles checked for specific reference to cancer by searching the full-text. The purpose of this additional screen was to identify reviews of generic relevance to in vitro cancer research that were not explicit in title/abstract descriptions or indexing.

Inclusion/exclusion criteria. Articles were included that met all of the following criteria:

- Title/abstract/article indicating a systematic review

- Included studies using in vitro research methods and/or an article described as a systematic review of in vitro studies

- Focus on cancer or relevant to cancer research (and including a discussion on relevance)

- Published in English

Articles that were not described by the authors as a systematic review, included other research methods (e.g., review of in vivo plus in vitro research), had no obvious or direct relevance to the cancer field or were published in languages other than English were excluded.

Data extraction and appraisal. Once relevant studies were identified, information was extracted on to a template. This included: area of focus, aim, whether the PRISMA framework was used, other guidelines or quality assessment criteria used, whether these frameworks were adapted or amended for assessment of in vitro studies, databases searched, strategy and search terms reported, inclusion criteria, screening and selection process, data extraction process and method of synthesis. Data was extracted by one author (MB or KP), and checked for accuracy by a second author (KP or GP).

Appraisal of each systematic review was carried out using a set of criteria originally developed for clinical studies. Based on 


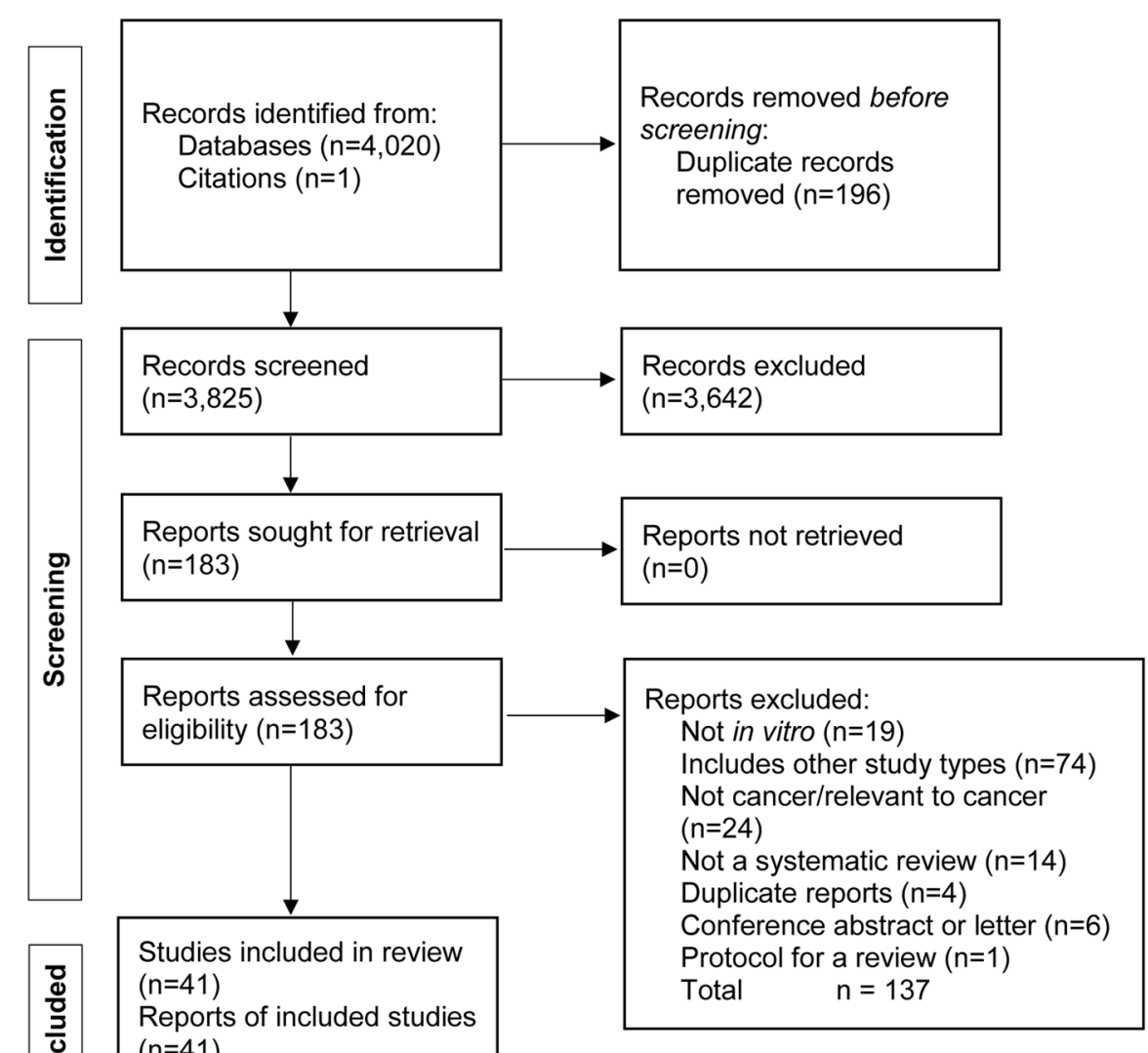

\section{Adapted from Page et al (70).}

Figure 1. PRISMA flow diagram for identification and screening of studies for review. Adapted from Page et al. (70).

AMSTAR (A MeaSurement Tool to Assess systematic Reviews) 2 'critical domains' (11), the following were assessed:

- adequacy of the literature search;

- justification for excluding individual studies by assessing if inclusion criteria were reported;

- risk of bias from individual studies being included in the review;

- effect on the interpretation of the results (by checking whether the quality of included studies had been assessed and if the result and impact of this assessment was referred to in the abstract);

We also recorded whether screening, selection and data extraction were appropriately done (including whether at least two researchers had been involved in each stage). Pre-registration of a protocol prior to commencing the review was not assessed, as there is currently no facility to register systematic reviews other than those involving human or animal studies (12). Publication bias was also not possible to assess.

\section{Results}

A total of 4,021 records were retrieved by the searches; after removal of duplicates (records in more than one database that related to the same paper), 3,825 remained, which were screened with reference to the inclusion/exclusion criteria. One hundred and eighty-three records were selected as possibly relevant. Two researchers (two of MB, KP and GP) independently assessed the full text of the papers. Of these, 41 were finally included (13-53). Figure 1 shows the screening process. Table II provides a summary of the basic characteristics. The assessment of the main methods and reporting of the reviews is presented in Table III.

Publication dates and journal of publication. The publication dates indicated an increasing number of systematic reviews of in vitro studies in recent years with 21 published since 2019, 12 between 2016 and 2018, 4 in the previous 3-year period and only 4 prior to 2013 . Reviews were published in the following types of journals: cancer-specific (10 reviews); pharmacology/toxicology/pharmaceutics related (4 reviews); general journals with broad scientific and medical scope (5 reviews); with the remainder published in a wide range of specialist journals. 
Table II. Focus and aim of included systematic reviews.

\begin{tabular}{|c|c|c|}
\hline Authors & Area of focus & Aim (page on which aim is stated) \\
\hline Asweto et al. 2017 (13) & Generic & $\begin{array}{l}\text { '(To) summarize(s) the apoptosis signal pathways and some ligands involved in SiNPs induced } \\
\text { apoptosis, and provides the current evidence of SiNPs induced apoptosis mechanisms' (p. 192) }\end{array}$ \\
\hline Barabadi et al. 2019a (14) & Colorectal & $\begin{array}{l}\text { 'To evaluate the anticancer potential of biologically synthesized } \\
\text { AuNPs against colorectal cancer cells' (p. 652) }\end{array}$ \\
\hline Barabadi et al. 2019b (15) & Lung & $\begin{array}{l}\text { 'To evaluate the anticancer potential of biologically synthesized } \\
\text { AuNPs against lung cancer' (p. } 323 \text { ) }\end{array}$ \\
\hline Barabadi et al. 2020 (16) & Hepatic & $\begin{array}{l}\text { 'To evaluate the anticancer activity of biogenic AuNPs against hepatic cancer cells' (p. 5) } \\
\text { (and the underlying molecular mechanisms) }\end{array}$ \\
\hline Batista-Napotnik et al. 2016 (17) & Generic & $\begin{array}{l}\text { 'To review published results in a systematic and comprehensive way... } \\
\text { statistical analysis of published results to determine whether nsEP of different } \\
\text { durations affect cells differently' (p. 2) }\end{array}$ \\
\hline Brown et al. 2021 (18) & Breast & $\begin{array}{l}\text { 'To summarize the direction and magnitude of effect sizes reported in the } \\
\text { existing body of literature that explore the role of exercise on modulating } \\
\text { breast cancer progression in vitro only' (p. 254) }\end{array}$ \\
\hline Bus et al. 2012 (19) & Oesophageal & $\begin{array}{l}\text { 'To review the literature on cell lines and incubation conditions } \\
\text { for studying BE development' (p. 149) }\end{array}$ \\
\hline Cardoso-Pavan et al. 2015 (20) & Head and neck & $\begin{array}{l}\text { 'To verify the in vitro anti-tumour effects of statins on head and neck squamous cell } \\
\text { carcinoma' (p2) Note: both in vitro and in vivo studies were included }\end{array}$ \\
\hline Chew et al. 2020 (21) & Thyroid & $\begin{array}{l}\text { 'To summarize how thyroid in vitro culture models have evolved and highlight how } \\
\text { in vitro models have been fundamental to thyroid cancer research' (p. 1) }\end{array}$ \\
\hline da Silva et al. 2020 (22) & Generic & $\begin{array}{l}\text { 'To conduct a systematic review regarding the use of PBM in tumoral cells, addressing } \\
\text { the different types of lasers and parameters used' (p. 524) }\end{array}$ \\
\hline de Campos et al. 2018 (23) & Cervical & $\begin{array}{l}\text { 'To identify validated reference genes currently used to normalize } \\
\text { RT-qPCR data in cervical cancer cell lines' (p. 139) }\end{array}$ \\
\hline Deng et al. 2016 (24) & Breast & $\begin{array}{l}\text { 'To evaluate the diagnostic accuracy of Raman spectroscopy system in the detection } \\
\text { of malignant breast lesions' (p. 1) Note: described as review of in vitro but ex vivo } \\
\text { and in vivo studies included }\end{array}$ \\
\hline Doktorovova et al. 2014 (25) & Generic & 'To compare the published results' (p. 2) (of in vitro studies on lipid nanoparticle carriers) \\
\hline Gianfredi et al. 2017a (26) & Breast & $\begin{array}{l}\text { 'To review the mechanisms whereby the epigenetic modifications induced by } \\
\text { bioactive dietary compounds will impact cancer cell survival' (p. 975) }\end{array}$ \\
\hline Gianfredi et al. 2017b (27) & Breast & 'To evaluate the effect of SFN and EGCG on breast cancer (BC) cells cultured in vitro' (p. 126) \\
\hline Gizzo et al. 2015 (28) & Endometrial & $\begin{array}{l}\text { 'To evaluate in vitro mechanisms of actions of RAL on normal (premenopausal human } \\
\text { endometrium) and neoplastic endometrial-derived cell lines (Ishikawa cell line) to } \\
\text { explain in vivo endometrial effects of RAL' (p. 498) }\end{array}$ \\
\hline Graybill et al. 2017 (29) & Various & $\begin{array}{l}\text { 'To provide a comprehensive analysis of published studies which details all cancerous } \\
\text { tissues tested for orexin receptor expression and the effects of orexin stimulation of } \\
\text { these receptors...' (p. 2) }\end{array}$ \\
\hline Gupta et al. 2019 (30) & Generic & $\begin{array}{l}\text { 'To present a systematic compilation of the in vitro cytotoxic and anticancer properties } \\
\text { of various } \mathrm{N} \text {-substituted isatins and illustrates their mechanism of action to overcome } \\
\text { MDR by acting as microtubule-destabilizing agents.'(p. 1) }\end{array}$ \\
\hline Hattori et al. 2019 (31) & Sarcoma & $\begin{array}{l}\text { 'To understand the present status of sarcoma cell lines and identify their current } \\
\text { challenges, we systematically reviewed reports on sarcoma cell lines' (p. 1) }\end{array}$ \\
\hline Kirkegaard et al. 2017 (32) & Colorectal & $\begin{array}{l}\text { 'To identify studies describing in vitro models used to investigate cancer cell } \\
\text { growth/proliferation, cell migration, cell invasion and cell death of serum taken } \\
\text { pre- and postoperatively from patients undergoing colorectal tumor resection' (p. 1) }\end{array}$ \\
\hline Laaksonen et al. 2010 (33) & Oral & $\begin{array}{l}\text { 'To review current knowledge on the effects on EMD on oral tissues, } \\
\text { particularly with respect to carcinoma' (p. 2) }\end{array}$ \\
\hline Ling et al. 2021 (34) & Generic & 'To reveal whether TiO2-NPs cause genotoxicity in vitro' (p. 2057) \\
\hline Malinowski et al. 2020 (35) & Generic & $\begin{array}{l}\text { 'in this systematic review recent evidence of metformin influence on miRNAs and } \\
\text { CSCs regulation in solid tumors will be discussed and summarized' (p. 2) }\end{array}$ \\
\hline Manfroi et al. 2020 (36) & Thyroid & $\begin{array}{l}\text { 'Evaluate data on the expression, location, and activity of GPER1, as well as } \\
\text { mechanisms mediating its effects in the thyroid' (p. 2) }\end{array}$ \\
\hline Mesas et al. 2021 (37) & Colon & $\begin{array}{l}\text { 'To analyze the antitumor activity of the bioactive components present in extracts from } \\
\text { Solanaceae and Cucurbitaceae families using different in in vitro models of colon cancer' (p. 1) }\end{array}$ \\
\hline Mondadori et al. 2020 (38) & Generic & $\begin{array}{l}\text { 'To provide an exhaustive summary of the advanced microfluidic 3D models that have } \\
\text { been designed to study the extravasation of cancer and immune cells...' (p. 1) }\end{array}$ \\
\hline Muller (Mueller) 2009 (39) & Generic & $\begin{array}{l}\text { 'reevaluation of the ability of various genetic toxicology in vitro tests to predict rodent } \\
\text { carcinogenicity and proposed changes to international guidelines governing their use' (p. 131) }\end{array}$ \\
\hline
\end{tabular}


Table II. Continued

\begin{tabular}{|c|c|c|}
\hline Authors & Area of focus & Aim (page on which aim is stated) \\
\hline Orange et al. 2020 (40) & Generic & $\begin{array}{l}\text { 'To systematically review and meta-analyze the effects of acute exercise-conditioned } \\
\text { serum on cancer cell growth in vitro' (p. 2) }\end{array}$ \\
\hline Peltanova et al. 2019 (41) & Head and neck & $\begin{array}{l}\text { 'focus on describing these major subpopulations of (immune) cells and other factors } \\
\text { influencing the TME and will discuss their function in the development of cancer, } \\
\text { in particular HNSCC' (p. 1) }\end{array}$ \\
\hline Prashanth et al. 2021 (42) & Brain & $\begin{array}{l}\text { 'To determine whether in vitro models can replace in vivo models to assess the brain } \\
\text { permeability of novel drugs for brain cancer' (p. 1) }\end{array}$ \\
\hline Raj et al. 2021 (43) & Generic & $\begin{array}{l}\text { 'To assess the effect of human MSC derived conditioned media (CM) } \\
\text { on human cancer cell lines' (p. 1) }\end{array}$ \\
\hline Raju et al. 2017 (44) & Generic & $\begin{array}{l}\text { 'To review original research articles using cancer cell lines as a tool to understand } \\
\text { carcinogenesis and to identify the genes involved in tumour development' (p. 2329) }\end{array}$ \\
\hline Raphaelli et al. 2020 (45) & Skin & $\begin{array}{l}\text { 'To investigate the protective role of fruit phytochemicals against melanoma skin } \\
\text { cancer from in vitro studies.' (p. 1009) }\end{array}$ \\
\hline Rego et al. 2017 (46) & Head and neck & $\begin{array}{l}\text { 'To summarize the available literature on the in vitro anti-tumour effects } \\
\text { of metformin on HNSCC' (p. 554) }\end{array}$ \\
\hline Rotelli et al. 2015 (47) & Colorectal & $\begin{array}{l}\text { 'To evaluate the in vitro effects (of the Mediterranean diet) on colorectal } \\
\text { cancer cell lines' (p. 145) }\end{array}$ \\
\hline Salamanna et al. 2016 (48) & Generic & $\begin{array}{l}\text { 'To summarise the current status of advanced and alternative 3D in vitro } \\
\text { bone metastases models' (p. 44803) }\end{array}$ \\
\hline Saravanan et al. 2020 (49) & Breast & $\begin{array}{l}\text { 'To evaluate the effectiveness of biogenic AuNPs for the treatment of breast cancer } \\
\text { and their anticancer molecular mechanisms through in vitro studies' (p. 3577) }\end{array}$ \\
\hline Stordal et al. 2009 (50) & Generic & $\begin{array}{l}\text { 'To determine which genetic modifications in cell lines have created the inverse } \\
\text { cisplatin/paclitaxel resistance phenotype' (p. 355) }\end{array}$ \\
\hline Tripodi et al. 2021 (51) & Skin & $\begin{array}{l}\text { 'This review systematically examines the current evidence describing the effects of } \\
\text { PBM on dermal fibroblasts in vitro'... 'to collate ..., to summate the effects..., } \\
\text { to analyze the strengths and weaknesses of the existing literature' (p. 2) }\end{array}$ \\
\hline Zhurakivska et al. 2018 (52) & Generic & $\begin{array}{l}\text { 'To summarize the data available in the scientific literature concerning the } \\
\text { in vitro activity of FWGE on malignant cells' (p. 1) }\end{array}$ \\
\hline Ziółkowska-Suchanek 2021 (53) & Lung & $\begin{array}{l}\text { 'To summarize the data in the field of NSCLC tumor hypoxia, including biology, } \\
\text { biomarkers, in vitro and in vivo studies and hypoxia imaging and detection' (p. 2) } \\
\text { Note: title indicates in vitro only }\end{array}$ \\
\hline
\end{tabular}

AuNP: Gold nanoparticles; BE: Barrett's esophagus; CSC: cancer stem cell; EMD: Emdogain; FWGE: fermented wheat germ extract; HNSCC: head and neck squamous cell carcinoma; MDR: multidrug-resistant; MSC: mesenchymal stem cell; NSCLC: non-small cell lung cancer; nsEP: nanosecond electric pulses; PBM: photobiomodulation; RAL: raloxifene; SiNPs: silica nanoparticles; TiO2-NPs: titanium dioxide nanoparticles; TME: tumor microenvironment; p.: page number.

Areas offocus. Table II shows the areas of focus for included reviews. Most frequently, the reviews focused on multiple cancers or had generic relevance (16 reviews). Where the type of cancer was specified, breast (5 reviews) $(18,24,26$, $27,49)$ and colorectal (4 reviews) $(14,32,37,47)$ were most frequent, followed by head and neck ( 3 reviews) $(20,41,46)$, lung (2 reviews) $(15,53)$, skin $(2$ reviews) $(45,51)$ and thyroid cancers (2 reviews) $(21,36)$, with single reviews on remaining cancers. Based on the stated aims, a range of aims were described including analysing, summarising, investigating, identifying, categorising, evaluating, verifying and comparing research on the specific topic.

Use of reporting guidelines. Twenty of the reviews claimed to be reported according to PRISMA guidelines and a further nine used the PRISMA flowchart (or similar) to show the process of selecting studies for inclusion. The remaining 12 did not mention PRISMA although one mentioned the Strengthening the Reporting of Observational Studies in Epidemiology guidelines (STROBE) (65). Of the 21 reviews published since 2019, 16 referred to PRISMA while 5 did not.

Databases searched. A range of databases was used to identify relevant studies to include in the systematic reviews. Four reviews did not report databases searched $(30,39,41,53)$. The three databases most frequently utilised were PubMed and/or MEDLINE $(n=37,90 \%)$, followed by Embase $(n=18,44 \%)$ and Web of Science/Web of Knowledge $(n=16,39 \%)$. Other databases reported to have been used in more than one review also included Scopus (13), Science Direct (8), Proquest (4), EBSCO (3), Google Scholar (3), CINAHL (2) and LILACS (Latin American and Caribbean Health Sciences) database (2). Several reported resources are publishers' repositories rather than true bibliographic databases (that is, they are platforms 
Table III. Analysis of the review methods and reporting.

\begin{tabular}{|c|c|c|c|c|c|c|c|c|c|}
\hline Authors & $\begin{array}{l}\text { Reported } \\
\text { as per } \\
\text { PRISMA }\end{array}$ & $\begin{array}{c}\text { Guidance or } \\
\text { criteria used } \\
\text { to assess } \\
\text { quality }\end{array}$ & $\begin{array}{c}\text { Databases } \\
\text { searched }\end{array}$ & $\begin{array}{l}\text { Reporting of } \\
\text { search (any } \\
\text { specific in vitro } \\
\text { search terms) }\end{array}$ & $\begin{array}{c}\text { Inclusion } \\
\text { criteria }\end{array}$ & $\begin{array}{l}\text { Screening and } \\
\text { selection } \\
\text { process } \\
\text { reporting }\end{array}$ & $\begin{array}{l}\text { Data } \\
\text { extraction } \\
\text { process } \\
\text { reporting }\end{array}$ & $\begin{array}{l}\text { Synthesis } \\
\text { of } \\
\text { results }\end{array}$ & $\begin{array}{c}\text { Reference } \\
\text { to } \\
\text { quality in } \\
\text { conclusions }\end{array}$ \\
\hline $\begin{array}{l}\text { Asweto et al. } \\
2017 \text { (13) }\end{array}$ & No* & $\begin{array}{l}\text { Guidelines for } \\
\text { assessing } \\
\text { in vitro } \\
\text { studies (54) }\end{array}$ & $\begin{array}{l}\text { WoS, PubMed, } \\
\text { Embase, CNKI }\end{array}$ & $\begin{array}{l}\text { Strategy and } \\
\text { terms reported }\end{array}$ & Reported & $\begin{array}{l}\text { People, } \\
\text { process, } \\
\text { numbers of } \\
\text { articles }\end{array}$ & $\begin{array}{l}\text { People, } \\
\text { process }\end{array}$ & $\begin{array}{l}\text { Narrative } \\
\text { plus tables }\end{array}$ & No \\
\hline $\begin{array}{l}\text { Barabadi et al. } \\
\text { 2019a (14) }\end{array}$ & Yes & $\begin{array}{c}\text { Not } \\
\text { reported }\end{array}$ & $\begin{array}{c}\text { Cochrane, WoS, } \\
\text { ProQuest, } \\
\text { PubMed, } \\
\text { Embase, Scopus, } \\
\text { Science Direct }\end{array}$ & $\begin{array}{l}\text { Terms only } \\
\text { reported } \\
(\text { cell line*) }\end{array}$ & Reported & $\begin{array}{l}\text { Process, } \\
\text { numbers of } \\
\text { articles }\end{array}$ & $\begin{array}{l}\text { Numbers } \\
\text { of people, } \\
\text { process, } \\
\text { data }\end{array}$ & $\begin{array}{l}\text { Narrative } \\
\text { plus tables }\end{array}$ & NA \\
\hline $\begin{array}{l}\text { Barabadi et al. } \\
\text { 2019b (15) }\end{array}$ & No* & $\begin{array}{c}\text { Not } \\
\text { reported }\end{array}$ & $\begin{array}{l}\text { Cochrane, WoS, } \\
\text { PubMed, Scopus, } \\
\text { Science Direct, } \\
\text { ProQuest, Embase }\end{array}$ & $\begin{array}{l}\text { Terms only } \\
\text { reported } \\
(\text { cell line*) }\end{array}$ & Reported & $\begin{array}{l}\text { Process, } \\
\text { numbers } \\
\text { of articles }\end{array}$ & Data & $\begin{array}{l}\text { Narrative } \\
\text { plus tables }\end{array}$ & NA \\
\hline $\begin{array}{l}\text { Barabadi et al. } \\
2020 \text { (16) }\end{array}$ & No* & $\begin{array}{c}\text { Not } \\
\text { reported }\end{array}$ & $\begin{array}{c}\text { PubMed, Scopus, } \\
\text { Embase, WoS, } \\
\text { Science Direct, } \\
\text { ProQuest, } \\
\text { Cochrane }\end{array}$ & $\begin{array}{l}\text { Terms only } \\
\text { reported } \\
(\text { cell line*) }\end{array}$ & Reported & $\begin{array}{l}\text { Numbers of } \\
\text { people, } \\
\text { process, } \\
\text { numbers of } \\
\text { articles }\end{array}$ & $\begin{array}{l}\text { Numbers } \\
\text { of people, } \\
\text { process, } \\
\text { data }\end{array}$ & $\begin{array}{l}\text { Narrative } \\
\text { plus } \\
\text { tables }\end{array}$ & NA \\
\hline $\begin{array}{l}\text { Batista-Napotnik } \\
\text { et al. } 2016 \text { (17) }\end{array}$ & No* & $\begin{array}{l}\text { Risk of bias } \\
\text { based on } \\
\text { Cochrane } \\
\text { criteria (55) } \\
\text { (Note: } 2008 \\
\text { version cited) }\end{array}$ & $\begin{array}{c}\text { Science Direct, } \\
\text { IEEE Xplore, } \\
\text { SpringerLink, } \\
\text { WoS, HighWire } \\
\text { Press, Compendex, } \\
\text { IngentaConnect, } \\
\text { PubMed }\end{array}$ & $\begin{array}{l}\text { Strategy and } \\
\text { terms } \\
\text { reported }\end{array}$ & Reported & $\begin{array}{l}\text { Process, } \\
\text { numbers of } \\
\text { articles }\end{array}$ & $\begin{array}{l}\text { People, } \\
\text { process, } \\
\text { data }\end{array}$ & $\begin{array}{c}\text { Narrative, } \\
\text { tables and } \\
\text { meta- } \\
\text { analysis }\end{array}$ & $\begin{array}{l}\text { No (but } \\
\text { high } \\
\text { risk of } \\
\text { bias studies } \\
\text { excluded } \\
\text { from } \\
\text { statistical } \\
\text { analysis) }\end{array}$ \\
\hline $\begin{array}{l}\text { Brown et al. } \\
2021 \text { (18) }\end{array}$ & Yes & $\begin{array}{l}\text { NTP OHAT } \\
\text { tool (56) and } \\
\text { criteria from } \\
\text { (57) }\end{array}$ & $\begin{array}{c}\text { MEDLINE, } \\
\text { PubMed, } \\
\text { EBSCO, } \\
\text { Cochrane, WoS, } \\
\text { BioMed Central }\end{array}$ & $\begin{array}{l}\text { Terms only } \\
\text { reported } \\
\text { (in vitro) }\end{array}$ & Reported & $\begin{array}{l}\text { People, } \\
\text { process, } \\
\text { numbers of } \\
\text { articles }\end{array}$ & $\begin{array}{l}\text { Numbers } \\
\text { of people, } \\
\text { process, } \\
\text { data. }\end{array}$ & $\begin{array}{c}\text { Narrative, } \\
\text { tables and } \\
\text { meta- } \\
\text { analysis }\end{array}$ & No \\
\hline $\begin{array}{l}\text { Bus et al. } \\
2012(19)\end{array}$ & No & $\begin{array}{c}\text { Not } \\
\text { reported }\end{array}$ & $\begin{array}{l}\text { PubMed, } \\
\text { Cochrane } \\
\text { library, } \\
\text { Embase }\end{array}$ & $\begin{array}{l}\text { Terms only } \\
\text { reported } \\
\text { (cell line, } \\
\text { culture) }\end{array}$ & Reported & $\begin{array}{l}\text { Numbers of } \\
\text { articles only }\end{array}$ & $\begin{array}{c}\text { Not } \\
\text { reported }\end{array}$ & $\begin{array}{l}\text { Narrative } \\
\text { plus tables }\end{array}$ & NA \\
\hline $\begin{array}{l}\text { Cardoso-Pavan } \\
\text { et al. } 2015(20)\end{array}$ & Yes & $\begin{array}{l}\text { GRADE (58) } \\
\text { (adapted for } \\
\text { in vitro) }\end{array}$ & $\begin{array}{c}\text { Cochrane, } \\
\text { MEDLINE, } \\
\text { Embase, LILACS, } \\
\text { PubMed }\end{array}$ & $\begin{array}{c}\text { Strategy } \\
\text { and terms } \\
\text { reported. }\end{array}$ & Reported & $\begin{array}{l}\text { People, } \\
\text { process, } \\
\text { numbers of } \\
\text { articles }\end{array}$ & $\begin{array}{l}\text { People, } \\
\text { process, } \\
\text { data }\end{array}$ & $\begin{array}{l}\text { Narrative } \\
\text { and tables }\end{array}$ & No \\
\hline $\begin{array}{l}\text { Chew et al. } \\
2020 \text { (21) }\end{array}$ & No* & $\begin{array}{c}\text { Not } \\
\text { reported }\end{array}$ & $\begin{array}{c}\text { Embase, } \\
\text { MEDLINE and } \\
\text { PubMed, } \\
\text { Google scholar }\end{array}$ & $\begin{array}{l}\text { Strategy and } \\
\text { terms } \\
\text { reported } \\
(\text { in vitro })\end{array}$ & Reported & $\begin{array}{l}\text { Numbers of } \\
\text { articles only }\end{array}$ & $\begin{array}{c}\text { Not } \\
\text { reported }\end{array}$ & $\begin{array}{l}\text { Narrative } \\
\text { and tables }\end{array}$ & NA \\
\hline $\begin{array}{l}\text { da Silva et al. } \\
2020(22)\end{array}$ & Yes & $\begin{array}{c}\text { Not } \\
\text { reported }\end{array}$ & $\begin{array}{c}\text { PubMed/ } \\
\text { MEDLINE, } \\
\text { Embase, Cochrane } \\
\text { Library }\end{array}$ & $\begin{array}{l}\text { Strategy and } \\
\text { terms } \\
\text { reported. }\end{array}$ & Reported & $\begin{array}{l}\text { Numbers of } \\
\text { people, } \\
\text { process, } \\
\text { numbers } \\
\text { of articles }\end{array}$ & $\begin{array}{c}\text { Numbers } \\
\text { of people, } \\
\text { process }\end{array}$ & $\begin{array}{l}\text { Narrative } \\
\text { and tables }\end{array}$ & NA \\
\hline $\begin{array}{l}\text { de Campos et al. } \\
2018 \text { (23) }\end{array}$ & No & $\begin{array}{c}\text { Not } \\
\text { reported }\end{array}$ & PubMed & $\begin{array}{l}\text { Strategy and } \\
\text { terms reported. }\end{array}$ & Reported & $\begin{array}{l}\text { Numbers of } \\
\text { articles only }\end{array}$ & $\begin{array}{c}\text { Not } \\
\text { reported }\end{array}$ & $\begin{array}{l}\text { Narrative } \\
\text { and tables }\end{array}$ & NA \\
\hline $\begin{array}{l}\text { Deng et al. } \\
2016 \text { (24) }\end{array}$ & Yes & $\begin{array}{c}\text { Risk of } \\
\text { bias using } \\
\text { (QUADAS-2) } \\
(59)\end{array}$ & $\begin{array}{l}\text { PubMed, } \\
\text { Embase }\end{array}$ & $\begin{array}{c}\text { Strategy and } \\
\text { terms reported. }\end{array}$ & Reported & $\begin{array}{l}\text { Process, } \\
\text { numbers } \\
\text { of articles }\end{array}$ & $\begin{array}{l}\text { Numbers } \\
\text { of people, } \\
\text { data }\end{array}$ & $\begin{array}{c}\text { Narrative, } \\
\text { tables and } \\
\text { meta- } \\
\text { analysis }\end{array}$ & No \\
\hline
\end{tabular}


Table III. Continued

\begin{tabular}{|c|c|c|c|c|c|c|c|c|c|}
\hline Authors & $\begin{array}{l}\text { Reported } \\
\text { as per } \\
\text { PRISMA }\end{array}$ & $\begin{array}{l}\text { Guidance or } \\
\text { criteria used } \\
\text { to assess } \\
\text { quality }\end{array}$ & $\begin{array}{c}\text { Databases } \\
\text { searched }\end{array}$ & $\begin{array}{l}\text { Reporting of } \\
\text { search (any } \\
\text { specific in vitro } \\
\text { search terms) }\end{array}$ & $\begin{array}{c}\text { Inclusion } \\
\text { criteria }\end{array}$ & $\begin{array}{l}\text { Screening and } \\
\text { selection } \\
\text { process } \\
\text { reporting }\end{array}$ & $\begin{array}{l}\text { Data } \\
\text { extraction } \\
\text { process } \\
\text { reporting }\end{array}$ & $\begin{array}{l}\text { Synthesis } \\
\text { of } \\
\text { results }\end{array}$ & $\begin{array}{c}\text { Reference } \\
\text { to } \\
\text { quality in } \\
\text { conclusions }\end{array}$ \\
\hline $\begin{array}{l}\text { Doktorovova et al. } \\
2014(25)\end{array}$ & . No & $\begin{array}{l}\text { Not } \\
\text { reported }\end{array}$ & $\begin{array}{l}\text { PubMed, } \\
\text { ISI Web of } \\
\text { Knowledge }\end{array}$ & $\begin{array}{l}\text { Strategy and } \\
\text { terms reported. }\end{array}$ & $\begin{array}{l}\text { Not } \\
\text { reported }\end{array}$ & $\begin{array}{l}\text { Not } \\
\text { reported }\end{array}$ & $\begin{array}{l}\text { Reported } \\
\text { data }\end{array}$ & $\begin{array}{l}\text { Narrative } \\
\text { and tables }\end{array}$ & NA \\
\hline $\begin{array}{l}\text { Gianfredi et al. } \\
\text { 2017a (26) }\end{array}$ & Yes & $\begin{array}{c}\text { Not reported } \\
\text { (mentions } \\
\text { quality but } \\
\text { used as } \\
\text { exclusion criteria) }\end{array}$ & $\begin{array}{l}\text { PubMed, } \\
\text { Scopus }\end{array}$ & $\begin{array}{l}\text { Strategy and } \\
\text { terms reported. }\end{array}$ & Reported & $\begin{array}{l}\text { People, } \\
\text { process, } \\
\text { numbers } \\
\text { of articles }\end{array}$ & $\begin{array}{l}\text { Not } \\
\text { reported }\end{array}$ & Narrative & NA \\
\hline $\begin{array}{l}\text { Gianfredi et al. } \\
2017 \mathrm{~b}(27)\end{array}$ & Yes & $\begin{array}{l}\text { Not reported } \\
\text { (except for: } \\
\text { tested in vitro at } \\
\text { least in triplicate; } \\
\text { clear description } \\
\text { of study design } \\
\text { and findings) }\end{array}$ & $\begin{array}{l}\text { PubMed/ } \\
\text { MEDLINE, } \\
\text { Scopus }\end{array}$ & $\begin{array}{l}\text { Strategy and } \\
\text { terms reported. }\end{array}$ & Reported & $\begin{array}{l}\text { People, } \\
\text { process, } \\
\text { numbers } \\
\text { of articles }\end{array}$ & $\begin{array}{l}\text { People, } \\
\text { process, } \\
\text { data }\end{array}$ & $\begin{array}{c}\text { Narrative, } \\
\text { tables and } \\
\text { meta- } \\
\text { analysis }\end{array}$ & No \\
\hline $\begin{array}{l}\text { Gizzo et al. } \\
2015 \text { (28) }\end{array}$ & No & $\begin{array}{l}\text { Not reported } \\
\text { (except for generic } \\
\text { statement on } \\
\text { reporting and data) }\end{array}$ & $\begin{array}{l}\text { MEDLINE, } \\
\text { Embase } \\
\text { ScienceDirect, } \\
\text { Cochrane Library }\end{array}$ & $\begin{array}{l}\text { Terms only } \\
\text { reported } \\
\text { (in vitro } \\
\text { activity) }\end{array}$ & $\begin{array}{l}\text { Partially } \\
\text { reported }\end{array}$ & $\begin{array}{c}\text { Numbers } \\
\text { of articles } \\
\text { only }\end{array}$ & $\begin{array}{l}\text { Not } \\
\text { reported }\end{array}$ & $\begin{array}{l}\text { Narrative } \\
\text { and tables }\end{array}$ & No \\
\hline $\begin{array}{l}\text { Graybill et al. } \\
2017 \text { (29) }\end{array}$ & $\begin{array}{l}\text { No* } \\
\\
b\end{array}$ & $\begin{array}{c}\text { Not reported } \\
\text { (except: assessed } \\
\text { for potential bias } \\
\text { based on funding or } \\
\text { author affiliations) }\end{array}$ & $\begin{array}{l}\text { PubMed, } \\
\text { EBSCO }\end{array}$ & $\begin{array}{l}\text { Strategy and } \\
\text { terms reported. }\end{array}$ & Reported & $\begin{array}{l}\text { Process, } \\
\text { numbers } \\
\text { of articles }\end{array}$ & $\begin{array}{l}\text { Not } \\
\text { reported }\end{array}$ & $\begin{array}{l}\text { Narrative } \\
\text { and tables }\end{array}$ & No \\
\hline $\begin{array}{l}\text { Gupta et al. } \\
2019 \text { (30) }\end{array}$ & No & $\begin{array}{l}\text { Not } \\
\text { reported }\end{array}$ & $\begin{array}{l}\text { Not } \\
\text { reported }\end{array}$ & $\begin{array}{l}\text { Not } \\
\text { reported }\end{array}$ & $\begin{array}{l}\text { Not } \\
\text { reported }\end{array}$ & $\begin{array}{l}\text { Not } \\
\text { reported }\end{array}$ & $\begin{array}{l}\text { Not } \\
\text { reported }\end{array}$ & $\begin{array}{c}\text { Narrative } \\
\text { (tables do } \\
\text { not refer } \\
\text { to studies) }\end{array}$ & NA \\
\hline $\begin{array}{l}\text { Hattori et al. } \\
2019 \text { (31) }\end{array}$ & No & $\begin{array}{l}\text { Not } \\
\text { reported }\end{array}$ & $\begin{array}{l}\text { Cellosaurus } \\
\text { (cell line } \\
\text { database); } \\
\text { PubMed }\end{array}$ & $\begin{array}{l}\text { Reported for } \\
\text { Cellosaurus } \\
\text { only }\end{array}$ & $\begin{array}{l}\text { Reported } \\
\text { for cell } \\
\text { lines only }\end{array}$ & $\begin{array}{c}\text { Numbers } \\
\text { of articles } \\
\text { only }\end{array}$ & $\begin{array}{l}\text { For cell } \\
\text { lines only }\end{array}$ & $\begin{array}{c}\text { Narrative } \\
\text { (tables do } \\
\text { not refer } \\
\text { to studies) }\end{array}$ & NA \\
\hline $\begin{array}{l}\text { Kirkegaard } \\
\text { et al. } 2017 \text { (32) }\end{array}$ & Yes & $\begin{array}{c}\text { Newcastle- } \\
\text { Ottawa } \\
\text { quality } \\
\text { assessment } \\
\text { (60) (adapted) }\end{array}$ & $\begin{array}{l}\text { PubMed, } \\
\text { Embase }\end{array}$ & $\begin{array}{l}\text { Strategy and } \\
\text { terms reported } \\
\text { (cell line) }\end{array}$ & Reported & $\begin{array}{l}\text { People, } \\
\text { process, } \\
\text { numbers } \\
\text { of articles }\end{array}$ & $\begin{array}{l}\text { Not } \\
\text { reported } \\
\text { except for } \\
\text { quality } \\
\text { assessment }\end{array}$ & $\begin{array}{l}\text { Narrative } \\
\text { and tables }\end{array}$ & No \\
\hline $\begin{array}{l}\text { Laaksonen et al. } \\
2010 \text { (33) }\end{array}$ & No & $\begin{array}{l}\text { Not } \\
\text { reported }\end{array}$ & $\begin{array}{l}\text { PubMed, } \\
\text { Embase }\end{array}$ & $\begin{array}{l}\text { Strategy and } \\
\text { terms reported. }\end{array}$ & Reported & $\begin{array}{c}\text { Numbers } \\
\text { of articles } \\
\text { only }\end{array}$ & $\begin{array}{l}\text { Not } \\
\text { reported }\end{array}$ & $\begin{array}{c}\text { Narrative } \\
\text { (tables do } \\
\text { not refer } \\
\text { to studies) }\end{array}$ & NA \\
\hline $\begin{array}{l}\text { Ling et al. } \\
2021 \text { (34) }\end{array}$ & No* & $\begin{array}{c}\text { ToxRTool } \\
\text { checklist } \\
(61)\end{array}$ & $\begin{array}{l}\text { PubMed, WoS, } \\
\text { Embase, CNKI, } \\
\text { Wan Fang, } \\
\text { VIP, CBM }\end{array}$ & $\begin{array}{l}\text { Strategy and } \\
\text { terms reported }\end{array}$ & Reported & $\begin{array}{l}\text { Process, } \\
\text { numbers } \\
\text { of articles }\end{array}$ & $\begin{array}{l}\text { People, } \\
\text { process, } \\
\text { data }\end{array}$ & $\begin{array}{c}\text { Narrative, } \\
\text { tables and } \\
\text { meta- } \\
\text { analysis }\end{array}$ & No \\
\hline $\begin{array}{l}\text { Malinowski et al. } \\
2020 \text { (35) }\end{array}$ & Yes & $\begin{array}{c}\text { Risk of } \\
\text { bias and } \\
\text { reporting using } \\
\text { criteria } \\
\text { from (62) }\end{array}$ & $\begin{array}{l}\text { PubMed, } \\
\text { MEDLINE }\end{array}$ & $\begin{array}{l}\text { Strategy and } \\
\text { terms reported }\end{array}$ & Reported & $\begin{array}{c}\text { People, } \\
\text { process, } \\
\text { numbers of } \\
\text { articles }\end{array}$ & $\begin{array}{l}\text { People, } \\
\text { process, } \\
\text { data }\end{array}$ & $\begin{array}{l}\text { Narrative } \\
\text { and tables }\end{array}$ & $\begin{array}{c}\text { Yes } \\
\text { (states } \\
\text { studies } \\
\text { had low } \\
\text { risk of bias) }\end{array}$ \\
\hline $\begin{array}{l}\text { Manfroi et al. } \\
2020 \text { (36) }\end{array}$ & Yes & $\begin{array}{c}\text { States that } \\
\text { quality not rated } \\
\text { because of } \\
\text { differences in } \\
\text { study designs }\end{array}$ & $\begin{array}{c}\text { PubMed, } \\
\text { Scielo, } \\
\text { Cochrane } \\
\text { Library }\end{array}$ & $\begin{array}{l}\text { Strategy and } \\
\text { terms reported. }\end{array}$ & Reported & $\begin{array}{l}\text { Numbers } \\
\text { of people, } \\
\text { process, } \\
\text { numbers } \\
\text { of articles }\end{array}$ & $\begin{array}{l}\text { Not } \\
\text { reported }\end{array}$ & $\begin{array}{l}\text { Narrative } \\
\text { and tables }\end{array}$ & NA \\
\hline
\end{tabular}


Table III. Continued

\begin{tabular}{|c|c|c|c|c|c|c|c|c|c|}
\hline Authors & $\begin{array}{l}\text { Reported } \\
\text { as per } \\
\text { PRISMA }\end{array}$ & $\begin{array}{l}\text { Guidance or } \\
\text { criteria used } \\
\text { to assess } \\
\text { quality }\end{array}$ & $\begin{array}{c}\text { Databases } \\
\text { searched }\end{array}$ & $\begin{array}{l}\text { Reporting of } \\
\text { search (any } \\
\text { specific in vitro } \\
\text { search terms) }\end{array}$ & $\begin{array}{l}\text { Inclusion } \\
\text { criteria }\end{array}$ & $\begin{array}{l}\text { Screening and } \\
\text { selection } \\
\text { process } \\
\text { reporting }\end{array}$ & $\begin{array}{l}\text { Data } \\
\text { extraction } \\
\text { process } \\
\text { reporting }\end{array}$ & $\begin{array}{c}\text { Synthesis } \\
\text { of } \\
\text { results }\end{array}$ & $\begin{array}{c}\text { Reference } \\
\text { to } \\
\text { quality in } \\
\text { conclusions }\end{array}$ \\
\hline $\begin{array}{l}\text { Mesas et al. } \\
2021 \text { (37) }\end{array}$ & Yes 2 & $\begin{array}{l}\text { 2-part questionnaire: } \\
\text { 1) filter questions } \\
\text { for in vitro } \\
\text { 2) quality of } \\
\text { the study }\end{array}$ & $\begin{array}{l}\text { PubMed, } \\
\text { SCOPUS, } \\
\text { WoS, Cochrane } \\
\text { Library }\end{array}$ & $\begin{array}{c}\text { Strategy and } \\
\text { terms reported. }\end{array}$ & Reported & $\begin{array}{l}\text { People, } \\
\text { process, } \\
\text { numbers of } \\
\text { articles }\end{array}$ & $\begin{array}{l}\text { People, } \\
\text { process, } \\
\text { data }\end{array}$ & $\begin{array}{l}\text { Narrative } \\
\text { and tables }\end{array}$ & No \\
\hline $\begin{array}{l}\text { Mondadori et al. } \\
2020 \text { (38) }\end{array}$ & No* & $\begin{array}{l}\text { Quality and risk } \\
\text { of bias assessed } \\
\text { by adapting } \\
\text { methods from } \\
(62) \text { and (63) }\end{array}$ & $\begin{array}{l}\text { PUBMED, } \\
\text { Embase }\end{array}$ & $\begin{array}{l}\text { Strategy and } \\
\text { terms reported } \\
\text { (microfluidic* } \\
\text { microscale/ } \\
\text { micro-scale* } \\
\text { organ-on-a-chip/ } \\
\text { organ-on-chip) }\end{array}$ & Reported & $\begin{array}{l}\text { People, } \\
\text { process, } \\
\text { numbers } \\
\text { of articles }\end{array}$ & $\begin{array}{l}\text { People, } \\
\text { process, } \\
\text { data }\end{array}$ & $\begin{array}{l}\text { Narrative } \\
\text { and tables }\end{array}$ & No \\
\hline Muller 2009 (39) & No & $\begin{array}{c}\text { Not } \\
\text { reported }\end{array}$ & $\begin{array}{c}\text { Not } \\
\text { reported }\end{array}$ & $\begin{array}{l}\text { Not } \\
\text { reported }\end{array}$ & $\begin{array}{c}\text { Not } \\
\text { reported }\end{array}$ & $\begin{array}{c}\text { Not } \\
\text { reported }\end{array}$ & $\begin{array}{c}\text { Not } \\
\text { reported }\end{array}$ & Narrative & $\begin{array}{l}\text { NA (but } \\
\text { mentions } \\
\text { ECVAM) }\end{array}$ \\
\hline $\begin{array}{l}\text { Orange et al. } \\
2020(40)\end{array}$ & Yes & $\begin{array}{c}\text { Risk of bias } \\
\text { using modified } \\
\text { RTI tool (64) }\end{array}$ & $\begin{array}{l}\text { PubMed, WoS, } \\
\text { Scopus, } \\
\text { SportDiscus, } \\
\text { CINAHL }\end{array}$ & $\begin{array}{l}\text { Strategy and } \\
\text { terms (cell line*, } \\
\text { in vitro) }\end{array}$ & Reported & $\begin{array}{l}\text { People, } \\
\text { process, } \\
\text { numbers of } \\
\text { articles }\end{array}$ & $\begin{array}{l}\text { People, } \\
\text { process, } \\
\text { data }\end{array}$ & $\begin{array}{c}\text { Narrative, } \\
\text { tables and } \\
\text { meta- } \\
\text { analysis }\end{array}$ & Yes \\
\hline $\begin{array}{l}\text { Peltanova et al. } \\
2019 \text { (41) }\end{array}$ & No & $\begin{array}{c}\text { Not } \\
\text { reported }\end{array}$ & $\begin{array}{l}\text { Not } \\
\text { reported }\end{array}$ & $\begin{array}{c}\text { Not } \\
\text { reported }\end{array}$ & $\begin{array}{c}\text { Not } \\
\text { reported }\end{array}$ & $\begin{array}{c}\text { Not } \\
\text { reported }\end{array}$ & $\begin{array}{c}\text { Not } \\
\text { reported }\end{array}$ & $\begin{array}{l}\text { Narrative } \\
\text { and tables }\end{array}$ & NA \\
\hline $\begin{array}{l}\text { Prashanth et al. } \\
2021 \text { (42) }\end{array}$ & Yes & $\begin{array}{c}\text { Not } \\
\text { reported }\end{array}$ & $\begin{array}{l}\text { PubMed, Embase, } \\
\text { MEDLINE, } \\
\text { Scopus }\end{array}$ & $\begin{array}{l}\text { Strategy and } \\
\text { terms reported } \\
\text { (in vitro mode*) }\end{array}$ & Reported & $\begin{array}{c}\text { Numbers } \\
\text { of articles } \\
\text { only }\end{array}$ & $\begin{array}{c}\text { Not } \\
\text { reported }\end{array}$ & $\begin{array}{l}\text { Narrative } \\
\text { and tables }\end{array}$ & NA \\
\hline $\begin{array}{l}\text { Raj et al. } \\
2021 \text { (43) }\end{array}$ & Yes & $\begin{array}{l}\text { Customized risk } \\
\text { of bias tool } \\
\text { was formulated }\end{array}$ & $\begin{array}{l}\text { PubMed, } \\
\text { SCOPUS, } \\
\text { WoS }\end{array}$ & $\begin{array}{l}\text { Strategy and } \\
\text { terms reported } \\
\quad \text { (in vitro) }\end{array}$ & Reported & $\begin{array}{l}\text { People, } \\
\text { process, } \\
\text { numbers of } \\
\text { articles }\end{array}$ & $\begin{array}{l}\text { People, } \\
\text { data }\end{array}$ & $\begin{array}{l}\text { Narrative } \\
\text { and tables }\end{array}$ & No \\
\hline $\begin{array}{l}\text { Raju et al. } \\
2017 \text { (44) }\end{array}$ & $\begin{array}{l}\text { No (but } \\
\text { refers to } \\
\text { STROBE } \\
\quad(65)\end{array}$ & $\begin{array}{c}\text { Not reported } \\
\text { except for } \\
\text { 'evaluation of } \\
\text { the methodo- } \\
\text { logies used and } \\
\text { assessed the } \\
\text { validation of the } \\
\text { study results' } \\
\text { (p2330) }\end{array}$ & $\begin{array}{c}\text { PubMed, } \\
\text { Google Scholar, } \\
\text { EBSCO, } \\
\text { Science Direct }\end{array}$ & $\begin{array}{l}\text { Terms only } \\
\text { reported } \\
\text { (cell lines) }\end{array}$ & Reported & $\begin{array}{l}\text { People, } \\
\text { process, } \\
\text { number } \\
\text { of articles }\end{array}$ & Some data & $\begin{array}{l}\text { Narrative } \\
\text { and tables }\end{array}$ & No \\
\hline $\begin{array}{l}\text { Raphaelli et al. } \\
2020 \text { (45) }\end{array}$ & Yes & $\begin{array}{c}\text { Not } \\
\text { reported }\end{array}$ & $\begin{array}{c}\text { PubMed/ } \\
\text { MEDLINE, } \\
\text { Bireme, WoS, } \\
\text { ScienceDirect. }\end{array}$ & $\begin{array}{l}\text { Strategy and } \\
\text { terms reported }\end{array}$ & Reported & $\begin{array}{l}\text { Numbers of } \\
\text { people, } \\
\text { process, } \\
\text { numbers of } \\
\text { articles }\end{array}$ & Data & $\begin{array}{l}\text { Narrative } \\
\text { and tables }\end{array}$ & NA \\
\hline $\begin{array}{l}\text { Rego et al. } \\
2017 \text { (46) }\end{array}$ & Yes & GRADE (58) & $\begin{array}{l}\text { Cochrane Library, } \\
\text { Embase, LILACS, } \\
\text { MEDLINE, } \\
\text { PubMed }\end{array}$ & $\begin{array}{c}\text { Strategy and } \\
\text {, terms reported. }\end{array}$ & Reported & $\begin{array}{l}\text { People, } \\
\text { process, } \\
\text { numbers of } \\
\text { articles }\end{array}$ & $\begin{array}{l}\text { People, } \\
\text { process, } \\
\text { data }\end{array}$ & $\begin{array}{l}\text { Narrative } \\
\text { and tables }\end{array}$ & No \\
\hline $\begin{array}{l}\text { Rotelli et al. } \\
2015 \text { (47) }\end{array}$ & No* & $\begin{array}{c}\text { Not } \\
\text { reported }\end{array}$ & $\begin{array}{l}\text { MEDLINE- } \\
\text { PubMed, } \\
\text { Scirus, } \\
\text { Google }\end{array}$ & $\begin{array}{l}\text { Strategy and } \\
\text { terms reported } \\
\text { (in vitro studies } \\
\text { in human } \\
\text { colorectal } \\
\text { carcinoma cells) }\end{array}$ & Reported & $\begin{array}{l}\text { Numbers of } \\
\text { articles } \\
\text { only }\end{array}$ & $\begin{array}{c}\text { Not } \\
\text { reported }\end{array}$ & $\begin{array}{c}\text { Narrative } \\
\text { (table does } \\
\text { not refer } \\
\text { to studies) }\end{array}$ & NA \\
\hline $\begin{array}{l}\text { Salamanna et al. } \\
2016 \text { (48) }\end{array}$ & Yes & $\begin{array}{c}\text { Not } \\
\text { reported }\end{array}$ & $\begin{array}{c}\text { PubMed, Scopus, } \\
\text { Web of } \\
\text { Knowledge }\end{array}$ & $\begin{array}{l}\text { Strategy and } \\
\text { terms reported }{ }^{* *}\end{array}$ & Reported & $\begin{array}{l}\text { Numbers of } \\
\text { articles } \\
\text { only }\end{array}$ & $\begin{array}{c}\text { Not } \\
\text { reported }\end{array}$ & $\begin{array}{l}\text { Narrative } \\
\text { and tables }\end{array}$ & NA \\
\hline
\end{tabular}


Table III. Continued

\begin{tabular}{|c|c|c|c|c|c|c|c|c|c|}
\hline Authors & $\begin{array}{l}\text { Reported } \\
\text { as per } \\
\text { PRISMA }\end{array}$ & $\begin{array}{l}\text { Guidance or } \\
\text { criteria used } \\
\text { to assess } \\
\text { quality }\end{array}$ & $\begin{array}{c}\text { Databases } \\
\text { searched }\end{array}$ & $\begin{array}{l}\text { Reporting of } \\
\text { search (any } \\
\text { specific in vitro } \\
\text { search terms) }\end{array}$ & $\begin{array}{c}\text { Inclusion } \\
\text { criteria }\end{array}$ & $\begin{array}{l}\text { Screening and } \\
\text { selection } \\
\text { process } \\
\text { reporting }\end{array}$ & $\begin{array}{l}\text { Data } \\
\text { extraction } \\
\text { process } \\
\text { reporting }\end{array}$ & $\begin{array}{l}\text { Synthesis } \\
\text { of } \\
\text { results }\end{array}$ & $\begin{array}{c}\text { Reference } \\
\text { to } \\
\text { quality in } \\
\text { conclusions }\end{array}$ \\
\hline $\begin{array}{l}\text { Saravanan et al. } \\
2020 \text { (49) }\end{array}$ & Yes & $\begin{array}{c}\text { Not } \\
\text { reported }\end{array}$ & $\begin{array}{c}\text { Cochrane, Scopus, } \\
\text { PubMed, WoS, } \\
\text { Science Direct, } \\
\text { ProQuest, } \\
\text { Embase }\end{array}$ & $\begin{array}{l}\text { Terms only } \\
\text { reported } \\
(\text { cell line*) }\end{array}$ & Reported & $\begin{array}{l}\text { Numbers of } \\
\text { people, } \\
\text { process, } \\
\text { numbers of } \\
\text { articles }\end{array}$ & $\begin{array}{l}\text { Numbers of } \\
\text { people, } \\
\text { process, } \\
\text { data }\end{array}$ & $\begin{array}{l}\text { Narrative } \\
\text { and tables }\end{array}$ & NA \\
\hline $\begin{array}{l}\text { Stordal et al. } \\
2009(50)\end{array}$ & No & $\begin{array}{c}\text { Not } \\
\text { reported }\end{array}$ & MEDLINE & $\begin{array}{l}\text { Terms only } \\
\text { reported } \\
\text { (cell line) }\end{array}$ & Reported & $\begin{array}{c}\text { Not } \\
\text { reported }\end{array}$ & $\begin{array}{l}\text { Not } \\
\text { reported }\end{array}$ & $\begin{array}{l}\text { Narrative } \\
\text { and tables }\end{array}$ & NA \\
\hline $\begin{array}{l}\text { Tripodi et al. } \\
2021 \text { (51) }\end{array}$ & Yes & $\begin{array}{l}\text { States that } \\
\text { risk of } \\
\text { bias not } \\
\text { carried out }\end{array}$ & $\begin{array}{c}\text { PubMed, Embase, } \\
\text { CINAHL, } \\
\text { SCOPUS, WoS }\end{array}$ & $\begin{array}{l}\text { Strategy and } \\
\text { terms } \\
\text { reported }\end{array}$ & Reported & $\begin{array}{l}\text { Numbers of } \\
\text { people, } \\
\text { process, } \\
\text { numbers of } \\
\text { articles }\end{array}$ & Data & $\begin{array}{l}\text { Narrative } \\
\text { and tables }\end{array}$ & NA \\
\hline $\begin{array}{l}\text { Zhurakivska et al. } \\
2018 \text { (52) }\end{array}$ & Yes & $\begin{array}{c}\text { Not } \\
\text { reported }\end{array}$ & $\begin{array}{c}\text { PubMed, } \\
\text { Scopus, WoS }\end{array}$ & $\begin{array}{l}\text { Strategy and } \\
\text { terms reported. }\end{array}$ & Reported & $\begin{array}{l}\text { Numbers of } \\
\text { people, } \\
\text { process, } \\
\text { numbers of } \\
\text { articles }\end{array}$ & $\begin{array}{l}\text { People, } \\
\text { data }\end{array}$ & $\begin{array}{l}\text { Narrative } \\
\text { and tables }\end{array}$ & NA \\
\hline $\begin{array}{l}\text { Ziółkowska- } \\
\text { Suchanek } \\
2021 \text { (53) }\end{array}$ & No & $\begin{array}{l}\text { Not } \\
\text { reported }\end{array}$ & $\begin{array}{l}\text { Not } \\
\text { reported }\end{array}$ & $\begin{array}{l}\text { Not } \\
\text { reported }\end{array}$ & $\begin{array}{l}\text { Not } \\
\text { reported }\end{array}$ & $\begin{array}{l}\text { Not } \\
\text { reported }\end{array}$ & $\begin{array}{l}\text { Not } \\
\text { reported }\end{array}$ & $\begin{array}{l}\text { Narrative } \\
\text { and tables }\end{array}$ & NA \\
\hline
\end{tabular}

*Except for flow chart based on PRISMA; **(three dimensional OR 3D OR 3d) AND (culture OR coculture OR model OR system OR in vitro culture OR in vitro co-culture OR in vitro model OR in vitro system); CNKI: China National Knowledge Infrastructure; ECVAM: European Centre for Validation of Alternative Methods; GRADE: Grading of Recommendations, Assessment, Development and Evaluations; NA: not applicable; NTP OHAT: National Toxicology Program's OHAT Risk of Bias Rating Tool for Human and Animal Studies; PRISMA: Preferred Reporting Items for Systematic Reviews and Meta-Analyses; QUADAS-2: revised tool for the Quality Assessment of Diagnostic Accuracy Studies; RTI: Research Triangle Institute (RTI) Item Bank for cross-sectional studies; STROBE: Strengthening the Reporting of Observational Studies in Epidemiology; WoS: Web of Science.

for accessing the collections of publications of specific publishers rather than the structured and indexed records from a wide range of publications found in bibliographic databases). The Cochrane Library/CENTRAL was used in 12 reviews, even though this database focuses primarily on systematic reviews of human clinical trials. The mean number of databases searched for all studies was three (range $=1-8$ ). Only two reviews involved a search of databases in a language other than English (Chinese) $(13,34)$ and two covered the Latin American and Caribbean literature $(20,46)$.

Search strategies. Thirty-six reviews $(88 \%)$ provided some information on how they had searched for relevant studies, while the remaining five provided no information on this. Of the 36 providing some information, nine provided only a list of search terms with no details on how these were combined as a strategy while both search terms and strategy were reported in the remaining 27 reviews. The strategies ranged from a simple approach in which terms representing the two main concepts were combined, to highly sophisticated strategies making full use of indexing terms, Boolean logic and other search techniques. Few strategies incorporated search terms that were specific for in vitro studies. Of those used, the terms in vitro (including in vitro, in vitro mode, in vitro model, in vitro activity) and 'cell line(s)' were the most frequently applied. Relevant indexing terms used by the National Library of Medicine to index MEDLINE records, such as In Vitro Techniques, Culture Techniques or more specific terms such as Cell Culture Techniques were not used.

Assessment of methods used to produce review. The majority of reviews $(35,85 \%)$ reported the inclusion criteria used in selecting studies, with only six not reporting this information. One review only reported cell lines included (31). In 26 reviews, at least minimal information was provided on the process of screening search results while, in 13 reviews, the numbers of records retrieved by the searches and the reviewers carrying out the screening of results were both reported. In a further 9 , only the numbers of records were reported and, in the remaining six, information on the screening and selection process was not presented. Thirteen reviews reported the process of data extraction and appraisal including the 
personnel involved and the data items extracted. Five reported two of the three items (people, process and data). Six reported only the data items extracted while one just reported cell lines. The remaining 16 reviews provided no details.

Quality assessment criteria. Only 13 reviews (32\%) incorporated a formal, structured assessment of the quality of the studies included in the review. Twenty-one reviews made no reference to quality assessment and two stated specifically that quality was not assessed $(36,51)$. One review reported using quality criteria which were used as exclusion criteria (26) while one or more generic criteria was used to assess studies for inclusion in three reviews (27-29); for example, statements such as "assessed for potential bias based on funding or author affiliations". Two reviews (35, 38) used criteria from previously published systematic reviews and one review (13) drew on criteria compiled from the results of a previously published scoping review on quality of toxicologically relevant studies (54). In two reviews, a customised risk of bias or quality tool was developed for use $(37,43)$.

Five reviews $(17,24,34,44,46)$ indicated that the following tools were used without any reported adaptations by review authors: Cochrane risk of bias (55); Quality Assessment of Diagnostic Accuracy Studies (QUADAS-2) (59); ToxRTool (61); STROBE (65); Grading of Recommendations, Assessment, Development and Evaluations (GRADE) (58) respectively. Authors of three reviews $(20,32,39)$ adapted or modified validated criteria for use with in vitro studies. These included GRADE (adapted for in vitro) (58); NewcastleOttawa quality assessment (adapted) (60), modified Research Triangle Institute (RTI) Item Bank for cross-sectional studies (64). In one case, the criteria were based on a combination of two sets of criteria: the National Toxicology Program's Office of Health Assessment and Translation (OHAT) Risk of Bias Rating Tool for Human and Animal Studies (56) and criteria from a published paper suggesting standards for in vitro research (57).

Existing quality assurance criteria were adapted by authors with the intention of increasing their relevance to in vitro methods. Adaptation to the GRADE framework was described thus: 'we have classified in vitro studies using comparable baselines, comparing them to the RCT studies published by Xiao et al. in 2013 using the GRADE method' (20). The authors noted the lack of standardised available criteria for assessment of in vitro studies. Adaptation of the Newcastle-Ottawa scale included adding an assessment of in vitro data collection methods and if cancer cells were used as the in vitro model system (32).

Methods for synthesis of the results. A narrative or descriptive approach was used in all reviews to present the overall results. Tables summarising the included studies (or selected characteristics of these) supplemented this in 35 reviews $(85 \%)$. Only six attempted a quantitative synthesis (meta-analysis).

\section{Discussion}

The aim of this investigation was to assess the quantity and quality of published reviews of in vitro studies described as systematic, and to investigate the quality assessment methods employed by review authors. We identified a relatively small number of completed systematic reviews relevant to cancer that focused on in vitro methods. This was consistent with expectations based on initial scoping searches.

The aims of the systematic reviews were very varied and, in some cases, it appeared that the main aim was simply to scope the field of research. This is not the main value of the systematic review approach, which has been designed to facilitate an objective, structured assessment of the research to answer a pre-specified question. The techniques that comprise a systematic review, however, such as comprehensive searching for research and clear presentation of the strengths and weaknesses of each study, may well be valuable in helping to collate research, reduce duplication and clearly demonstrate advances (and limitations) in techniques. Nevertheless, for systematic reviews of in vitro research to be effective, searching for relevant research must be comprehensive so that there is no bias in the set of studies included or omission of key studies.

The core AMSTAR 2 criteria include 'Adequacy of the literature search' but, while many reviews reported a search strategy, few were optimal or made use of the search facilities available. This suggests that more use could be made of specialist information staff and/or training for researchers in the field. While search strategies (use of AND/OR operators to combine terms, for example) were reported in 36 reviews (88\%), most reported generic searches without describing strategies for each database and, therefore, it is not possible to assess if and how changes to the strategies may have affected the results. Given that the average number of databases searched in included reviews was three (range $=1-8$ ), this reporting standard was relevant to the majority of cases here considered.

While the majority of researchers carrying out reviews searched either PubMed or MEDLINE, there was limited use of other databases. This includes those with a specific focus on pre-clinical or basic biological research which may be relevant to reviews of studies using in vitro methods. At present, much reliance is placed on one source (the MEDLINE database either in this format or via the PubMed interface). Other databases may improve searches: in the clinical field, this is certainly true (66) but may also be the case for in vitro research. For example, Embase covers nearly 3,000 journals that are not covered by MEDLINE 
(and has been particularly focused on pharmacology and related literature). Further research may be necessary to quantify the effect that exclusion of this and other databases may have on evidence retrieval for in vitro reviews. Similarly, few review teams made use of specific index terms as search terms even though these have the potential to improve the efficiency of searching. This step is crucial for ensuring the reviews offer a truly systematic overview of available evidence, and minimise related risks (e.g., unnecessary replication, failure to identify key findings relevant to future study designs, selection bias in papers included in meta-analyses).

It is also recommended that systematic reviews justify including and excluding individual studies by reporting inclusion criteria. The majority (35) did report the inclusion criteria. The number of records retrieved and screened were also reported by many of the reviews and this increases transparency of the searching and selection processes, i.e., how effectively the review team identified the relevant studies. Fewer reviews (18) reported how the studies were treated; little information was provided on what data was extracted from each study and how this was done. The lack of relevant data may be due to limitations in reporting in the original studies. One systematic analysis specifically focused on the challenges of conducting systematic reviews of in vitro studies found that insufficient reporting of essential cell culture parameters prevented cross-study comparisons (67).

The most noticeable difference between these reviews and the key indicators of an effective systematic review was in quality assessment of included studies. A previous analysis of systematic reviews of in vitro research in a wide range of areas found that only $29.2 \%$ (19/65) reported data on risk of bias (quality) for each study (10). In the current analysis, less than half of the reviews carried out any assessment of quality and less than a third included a formal, structured assessment. The lack of widely accepted quality criteria was also very apparent as a wide range of different tools and techniques were used. In some cases, authors produced their own checklist while in others, criteria were adapted from existing checklists in the clinical field.

Criteria have previously been proposed that specifically focused on the in vitro methods comprising items including clear delineation of cell viability, cell type, culture medium and constituents (67). Other authors have found it necessary to add their own guiding examples to generic criteria, e.g., for the criterion 'Clear description of research setting', Rahman et al. added the following examples: 'Culture setup, name and type of insert membrane, temperature' (68). Only a minority of reviews used published criteria for assessment of quality in included studies and 13 different sets of criteria were employed. Of particular note were the three reviews in which authors adapted quality assessment criteria developed for use in evaluation of clinical research.
The justification given in these cases was that such criteria were not appropriate to in vitro studies in their original form. This indicates an area for further investigation with regard to the applicability of more general quality criteria within this field. Lastly, even when quality was assessed, there was minimal reference to this when presenting conclusions. This means that it is not possible to assess the effect on the interpretation of the results.

Limitations in reporting may be linked to the comparatively low use of established reporting criteria for systematic review in the included studies, as poor reporting of systematic reviews of in vitro studies has previously been identified (10). While the numbers of such publications had increased over a 10-year period, reporting quality was not significantly improved over the same period. This current analysis found that while there was increasing reference to the PRISMA reporting guidelines over recent years, the potential for significant improvement in reporting was also revealed.

Finally, several reviews were described as systematic even though they exhibited none of the characteristics of such a review. For example, no methods section was present nor were indications of how studies were identified, selected or assessed. It is important that the description systematic review is restricted to those reviews that are conducted according to generally agreed methods.

Recommendations from this review are the following: 1. The description 'systematic review' is restricted to those reviews that include methods for identifying, selecting, and assessing included studies; 2. Searches for studies are carried out on more than one database and make use of wellconstructed search strategies; 3 . Methods for screening, data extraction, and quality assessment are reported (and preferably involve more than one reviewer/researcher); 4. Criteria for the assessment of in vitro research are adopted; 5. Results of the above stages are reported appropriately; 6 . Conclusions refer to quality of the included studies.

Further to this, reporting guidelines that are better suited to the in vitro field are required. These could take the form of a PRISMA extension, which has been used widely in other fields to adapt these general guidelines for specific contexts (e.g., PRISMA extension for Ecology and Evolutionary Biology), that includes criteria such as: Describe the type of replication unit (e.g. individuals, broods, study sites) (69).

Limitations in this review relate to the challenges in identifying studies using in vitro methods and in determining relevance to cancer. In order to focus on systematic reviews of in vitro studies, we excluded a large number of reviews that discussed in vitro studies alongside other study types and this resulted in a small number of reviews for this analysis. To extend the range of reviews assessed, we included those that made specific reference to relevance to cancer. However, this required examination of the full text of each article and further potentially relevant reviews may have been omitted. Lack of 
standards for systematic reviews of in vitro studies also impacted on assessment of methods, therefore, criteria were adapted from a tool widely used for clinical studies. Nevertheless, the results indicate that there is potential value in the systematic review approach to address a range of pertinent questions: this has already led to international efforts to develop appropriate techniques in the field of animal research and development of the approach now needs to receive a similar level of attention in the cancer in vitro field.

This review article indicates that concerns regarding consistency in application of reporting and quality assurance criteria in primary in vitro studies are also relevant to reviews of those studies relating to research in cancer. The present study makes several contributions. Firstly, it is, to our knowledge, the first study to provide a review of current practice and reporting standards in systematic reviews of cancer-related in vitro studies. It provided further support for findings of an initial exploratory search, that reporting standards for evidence retrieval and quality assessment are highly variable and that lack of common quality assessment criteria for assessment across studies is a limitation for reviewers. It also demonstrates that there is an interest in the use of the systematic review method in the field and that efforts to develop and adapt current approaches to the needs of the in vitro field would be of value. Further development of the systematic review approach is now required to optimise its use and value in the in vitro field and overcome the current limitations. This will require development and use of robust search strategies, appropriate quality assessment tools and researchers with the relevant skills.

\section{Conflicts of Interest}

The Authors have no conflicts of interest to declare in relation to this study.

\section{Authors' Contributions}

Karen Pilkington conceived the study and designed the searches. All Authors were involved in the screening and selection process, and data extraction and analysis. Mike Bracher drafted the paper and all authors revised the paper and contributed to the final manuscript.

\section{Acknowledgements}

Mike Bracher's position was funded by a grant from Animal Free Research UK. The funding body had no role in the design of the study or collection, analysis, and interpretation of data or in writing the manuscript.

\section{References}

1 Bartholomew M: James Lind's treatise of the scurvy (1753). Postgrad Med J 78(925): 695-696, 2002. PMID: 12496338. DOI: $10.1136 /$ pmj.78.925.695
2 Cochrane AL: Effectiveness \& Efficiency: Random Reflections on Health Services. Rock Carling fellowship; Taylor \& Francis, 1972.

3 CRD (Centre for Reviews and Dissemination) Systematic Reviews: CRD's Guidance for Undertaking Reviews in Health Care; Centre for Reviews and Dissemination, University of York, Vol. 10, 2009.

4 Moher D, Liberati A, Tetzlaff J, Altman DG and PRISMA Group: Preferred reporting items for systematic reviews and meta-analyses: the PRISMA statement. PLoS Med 6(7): e1000097, 2009. PMID: 19621072. DOI: 10.1371/journal. pmed.1000097

5 CASP Critical Appraisal Skills Programme (CASP). Available at: https://casp-uk.net/ [Last accessed on October 1st, 2020]

6 Higgins JPT, López-López JA, Becker BJ, Davies SR, Dawson S, Grimshaw JM, McGuinness LA, Moore THM, Rehfuess EA, Thomas J and Caldwell DM: Synthesising quantitative evidence in systematic reviews of complex health interventions. BMJ Glob Health 4(Suppl 1): e000858, 2019. PMID: 30775014. DOI: 10.1136/bmjgh-2018-000858

7 CAMARADES (Collaborative Approach to Meta-Analysis and Review of Animal Data from Experimental Studies). Available at: http://www.den.ed.ac.uk/camarades/ [Last accessed on February 1st, 2020]

8 Kilkenny C, Browne WJ, Cuthill IC, Emerson M and Altman DG: Improving bioscience research reporting: the ARRIVE guidelines for reporting animal research. PLoS Biol 8(6): e1000412, 2010. PMID: 20613859. DOI: 10.1371/journal.pbio.1000412

9 EBTC Evidence-Based Toxicology Collaboration. Available at: http://www.ebtox.org/ [Last accessed on October 1st, 2020]

10 Elshafay A, Omran ES, Abdelkhalek M, El-Badry MO, Eisa HG, Fala SY, Dang T, Ghanem MAT, Elbadawy M, Elhady MT, Vuong NL, Hirayama K and Huy NT: Reporting quality in systematic reviews of in vitro studies: a systematic review. Curr Med Res Opin 35(9): 1631-1641, 2019. PMID: 30977685. DOI: 10.1080/03007995.2019.1607270

11 Shea BJ, Reeves BC, Wells G, Thuku M, Hamel C, Moran J, Moher D, Tugwell P, Welch V, Kristjansson E and Henry DA: AMSTAR 2: a critical appraisal tool for systematic reviews that include randomised or non-randomised studies of healthcare interventions, or both. BMJ 358: j4008, 2017. PMID: 28935701. DOI: $10.1136 / \mathrm{bmj} . j 4008$

12 PROSPERO International prospective register of systematic reviews. Available at: https://www.crd.york.ac.uk/prospero/ [Last accessed on October 1st, 2020]

13 Asweto CO, Wu J, Alzain MA, Hu H, Andrea S, Feng L, Yang $\mathrm{X}$, Duan $\mathrm{J}$ and Sun Z: Cellular pathways involved in silica nanoparticles induced apoptosis: A systematic review of in vitro studies. Environ Toxicol Pharmacol 56: 191-197, 2017. PMID: 28957724. DOI: $10.1016 /$ j.etap.2017.09.012

14 Barabadi H, Vahidi H, Damavandi kamali K, Rashedi M, Hosseini $\mathrm{O}$ and Saravanan M: Emerging theranostic gold nanomaterials to combat colorectal cancer: a systematic review. Journal of Cluster Science 31(4): 651-658, 2020. DOI: 10.1007/s10876-019-01681-x

15 Barabadi H, Vahidi H, Damavandi kamali K, Hosseini O, Mahjoub M, Rashedi M, Jazayeri shoushtari F and Saravanan M: Emerging theranostic gold nanomaterials to combat lung cancer: a systematic review. Journal of Cluster Science 31(2): 323-330, 2020. DOI: 10.1007/s10876-019-01650-4 
16 Barabadi H, Webster TJ, Vahidi H, Sabori H, Damavandi Kamali K, Jazayeri Shoushtari F, Mahjoub MA, Rashedi M, Mostafavi E, Cruz DM, Hosseini $\mathrm{O}$ and Saravana M: Green nanotechnology-based gold nanomaterials for hepatic cancer therapeutics: a systematic review. Iran J Pharm Res 19(3): 3-17, 2020. PMID: 33680005. DOI: 10.22037/ijpr.2020.113820.14504

17 Batista Napotnik T, Reberšek M, Vernier PT, Mali B and Miklavčič D: Effects of high voltage nanosecond electric pulses on eukaryotic cells (in vitro): A systematic review. Bioelectrochemistry 110: 1-12, 2016. PMID: 26946156. DOI: 10.1016/j.bioelechem.2016.02.011

18 Brown MJ, Morris MA and Akam EC: An exploration of the role of exercise in modulating breast cancer progression in vitro: a systematic review and meta-analysis. Am J Physiol Cell Physiol 320(3): C253-C263, 2021. PMID: 33356943. DOI: 10.1152/ ajpcell.00461.2020

19 Bus P, Siersema PD and van Baal JW: Cell culture models for studying the development of Barrett's esophagus: a systematic review. Cell Oncol (Dordr) 35(3): 149-161, 2012. PMID: 22476962. DOI: 10.1007/s13402-012-0076-6

20 Pavan LM, Rêgo DF, Elias ST, De Luca Canto G and Guerra $\mathrm{EN}$ : In vitro anti-tumor effects of statins on head and neck squamous cell carcinoma: a systematic review. PLoS One 10(6): e0130476, 2015. PMID: 26098683. DOI: 10.1371/journal.pone. 0130476

21 Chew D, Green V, Riley A, England RJ and Greenman J: The changing face of in vitro culture models for thyroid cancer research: a systematic literature review. Front Surg 7: 43, 2020. PMID: 32766274. DOI: 10.3389/fsurg.2020.00043

22 da Silva JL, Silva-de-Oliveira AFS, Andraus RAC and Maia LP: Effects of low level laser therapy in cancer cells-a systematic review of the literature. Lasers Med Sci 35(3): 523-529, 2020. PMID: 31209588. DOI: 10.1007/s10103-019-02824-2

23 de Campos RP, Schultz IC, de Andrade Mello P, Davies S, Gasparin MS, Bertoni APS, Buffon A and Wink MR: Cervical cancer stem-like cells: systematic review and identification of reference genes for gene expression. Cell Biol Int 42(2): 139152, 2018. PMID: 28949053. DOI: 10.1002/cbin.10878

24 Deng K, Zhu C, Ma X, Jia H, Wei Z, Xiao Y and Xu J: Rapid discrimination of malignant breast lesions from normal tissues utilizing raman spectroscopy system: a systematic review and meta-analysis of in vitro studies. PLoS One 11(7): e0159860, 2016. PMID: 27459193. DOI: 10.1371/journal.pone.0159860

25 Doktorovova S, Souto EB and Silva AM: Nanotoxicology applied to solid lipid nanoparticles and nanostructured lipid carriers - a systematic review of in vitro data. Eur J Pharm Biopharm 87(1): 1-18, 2014. PMID: 24530885. DOI: 10.1016/ j.ejpb.2014.02.005

26 Gianfredi V, Nucci D, Vannini S, Villarini M and Moretti M: In vitro biological effects of sulforaphane (SFN), epigallocatechin3-gallate (EGCG), and curcumin on breast cancer cells: a systematic review of the literature. Nutr Cancer 69(7): 969-978, 2017. PMID: 28872903. DOI: 10.1080/01635581.2017.1359322

27 Gianfredi V, Vannini S, Moretti M, Villarini M, Bragazzi NL, Izzotti A and Nucci D: Sulforaphane and epigallocatechin gallate restore estrogen receptor expression by modulating epigenetic events in the breast cancer cell line MDA-MB-231: a systematic review and meta-analysis. J Nutrigenet Nutrigenomics 10(3-4): 126-135, 2017. PMID: 29040973. DOI: $10.1159 / 000480636$
28 Gizzo S, Noventa M, Di Gangi S, Litta P, Saccardi C, D’Antona $\mathrm{D}$ and Nardelli GB: Could in vitro studies on Ishikawa cell lines explain the endometrial safety of raloxifene? Systematic literature review and starting points for future oncological research. Eur J Cancer Prev 24(6): 497-507, 2015. PMID: 25536299. DOI: 10.1097/CEJ.0000000000000107

29 Graybill NL and Weissig V: A review of orexin's unprecedented potential as a novel, highly-specific treatment for various localized and metastatic cancers. SAGE Open Med 5: 2050312117735774 , 2017. PMID: 29147564. DOI: 10.1177/2050312117735774

30 Gupta AK, Tulsyan S, Bharadwaj M and Mehrotra R: Systematic review on cytotoxic and anticancer potential of N-substituted isatins as novel class of compounds useful in multidrug-resistant cancer therapy: In silico and in vitro analysis. Top Curr Chem (Cham) 377(3): 15, 2019. PMID: 31073777. DOI: 10.1007/s410 61-019-0240-9

31 Hattori E, Oyama R and Kondo T: Systematic review of the current status of human sarcoma cell lines. Cells 8(2): 157, 2019. PMID: 30781855. DOI: 10.3390/cells8020157

32 Kirkegaard T, Gögenur M and Gögenur I: Assessment of perioperative stress in colorectal cancer by use of in vitro cell models: a systematic review. PeerJ 5: e4033, 2017. PMID: 29158975. DOI: $10.7717 /$ peerj.4033

33 Laaksonen M, Sorsa T and Salo T: Emdogain in carcinogenesis: a systematic review of in vitro studies. J Oral Sci 52(1): 1-11, 2010. PMID: 20339227. DOI: 10.2334/josnusd.52.1

34 Ling C, An H, Li L, Wang J, Lu T, Wang H, Hu Y, Song G and Liu S: Genotoxicity evaluation of titanium dioxide nanoparticles in vitro: a systematic review of the literature and meta-analysis. Biol Trace Elem Res 199(5): 2057-2076, 2021. PMID: 32770326. DOI: $10.1007 / \mathrm{s} 12011-020-02311-8$

35 Malinowski B, Musiała N and Wiciński M: Metformin's modulatory effects on miRNAs function in cancer stem cells-a systematic review. Cells 9(6): 1401, 2020. PMID: 32512882. DOI: 10.3390/cells9061401

36 Manfroi PA, Bertoni APS and Furlanetto TW: GPER1 in the thyroid: A systematic review. Life Sci 241: 117112, 2020. PMID: 31790688. DOI: 10.1016/j.lfs.2019.117112

37 Mesas C, Fuel M, Martínez R, Prados J, Melguizo C and Porres JM: In vitro evidence of the antitumor capacity of Solanaceae and Cucurbitaceae in colon cancer: A systematic review. Crit Rev Food Sci Nutr: 1-22, 2021. PMID: 33739207. DOI: 10.1080/10408398.2021.1900058

38 Mondadori C, Crippa M, Moretti M, Candrian C, Lopa S and Arrigoni C: Advanced microfluidic models of cancer and immune cell extravasation: a systematic review of the literature. Front Bioeng Biotechnol 8: 907, 2020. PMID: 32984267. DOI: 10.3389/fbioe. 2020.00907

39 Müller L: 4.3 In-vitro genotoxicity tests to detect carcinogenicity: a systematic review. Hum Exp Toxicol 28(2-3): 131-133, 2009. PMID: 19713378. DOI: 10.1177/0960327109105770

40 Orange ST, Jordan AR and Saxton JM: The serological responses to acute exercise in humans reduce cancer cell growth in vitro: A systematic review and meta-analysis. Physiol Rep 8(22): e14635, 2020. PMID: 33207085. DOI: 10.14814/phy2.14635

41 Peltanova B, Raudenska M and Masarik M: Effect of tumor microenvironment on pathogenesis of the head and neck squamous cell carcinoma: a systematic review. Mol Cancer 18(1): 63, 2019. PMID: 30927923. DOI: 10.1186/s12943-0190983-5 
42 Prashanth A, Donaghy H, Stoner SP, Hudson AL, Wheeler HR, Diakos CI, Howell VM, Grau GE and McKelvey KJ: Are in vitro human blood-brain-tumor-barriers suitable replacements for in vivo models of brain permeability for novel therapeutics? Cancers (Basel) 13(5): 955, 2021. PMID: 33668807. DOI: 10.3390/cancers 13050955

43 Raj AT, Kheur S, Bhonde R, Gupta AA and Patil S: Assessing the effect of human mesenchymal stem cell-derived conditioned media on human cancer cell lines: A systematic review. Tissue Cell 71: 101505, 2021. PMID: 33582384. DOI: 10.1016/j.tice.2021.101505

44 Raju K L, Augustine D, Rao RS, S V S, Haragannavar VC, Nambiar S, Prasad K, Awan KH and Patil S: Biomarkers in tumorigenesis using cancer cell lines: a systematic review. Asian Pac J Cancer Prev 18(9): 2329-2337, 2017. PMID: 28950674. DOI: 10.22034/APJCP.2017.18.9.2329

45 De O. Raphaelli C, Azevedo J, Dalmazo G, Vinholes J, Braganhol E, Vizzotto M and Nora L: Effect of fruit secondary metabolites on melanoma: a systematic review of in vitro studies. Current Bioactive Compounds 16(7): 1009-1035, 2021. DOI: $10.2174 / 1573407215666190808113341$

46 Rêgo DF, Elias ST, Amato AA, Canto GL and Guerra EN: Antitumor effects of metformin on head and neck carcinoma cell lines: A systematic review. Oncol Lett 13(2): 554-566, 2017. PMID: 28356929. DOI: 10.3892/ol.2016.5526

47 Rotelli MT, Bocale D, De Fazio M, Ancona P, Scalera I, Memeo R, Travaglio E, Zbar AP and Altomare DF: IN-VITRO evidence for the protective properties of the main components of the Mediterranean diet against colorectal cancer: A systematic review. Surg Oncol 24(3): 145-152, 2015. PMID: 26303826. DOI: $10.1016 /$ j.suronc.2015.08.001

48 Salamanna F, Contartese D, Maglio M and Fini M: A systematic review on in vitro 3D bone metastases models: A new horizon to recapitulate the native clinical scenario? Oncotarget 7(28): 4480344820, 2016. PMID: 27027241. DOI: 10.18632/oncotarget.8394

49 Saravanan M, Vahidi H, Medina Cruz D, Vernet-Crua A, Mostafavi E, Stelmach R, Webster TJ, Mahjoub MA, Rashedi M and Barabadi $\mathrm{H}$ : Emerging antineoplastic biogenic gold nanomaterials for breast cancer therapeutics: a systematic review. Int J Nanomedicine 15: 3577-3595, 2020. PMID: 32547015. DOI: $10.2147 /$ IJN.S240293

50 Stordal B and Davey R: A systematic review of genes involved in the inverse resistance relationship between cisplatin and paclitaxel chemotherapy: role of BRCA1. Curr Cancer Drug Targets 9(3): 354-365, 2009. PMID: 19442054. DOI: 10.2174/15680090 9788166592

51 Tripodi N, Corcoran D, Antonello P, Balic N, Caddy D, Knight A, Meehan C, Sidiroglou F, Fraser S, Kiatos D, Husaric M, Apostolopoulos $\mathrm{V}$ and Feehan J: The effects of photobiomodulation on human dermal fibroblasts in vitro: A systematic review. J Photochem Photobiol B 214: 112100, 2021. PMID: 33316625. DOI: 10.1016/j.jphotobiol.2020.112100

52 Zhurakivska K, Troiano G, Caponio VCA, Dioguardi M, Arena C and Lo Muzio L: The effects of adjuvant fermented wheat germ extract on cancer cell lines: a systematic review. Nutrients 10(10): 1546, 2018. PMID: 30347664. DOI: 10.3390/nu10101546

53 Ziółkowska-Suchanek I: Mimicking tumor hypoxia in non-small cell lung cancer employing three-dimensional in vitro models. Cells 10(1): 141, 2021. PMID: 33445709. DOI: 10.3390/cells10010141

54 Samuel GO, Hoffmann S, Wright RA, Lalu MM, Patlewicz G, Becker RA, DeGeorge GL, Fergusson D, Hartung T, Lewis RJ and Stephens ML: Guidance on assessing the methodological and reporting quality of toxicologically relevant studies: A scoping review. Environ Int 92-93: 630-646, 2016. PMID: 27039952. DOI: 10.1016/j.envint.2016.03.010

55 Higgins JP, Altman DG, Gøtzsche PC, Jüni P, Moher D, Oxman AD, Savovic J, Schulz KF, Weeks L, Sterne JA, Cochrane Bias Methods Group and Cochrane Statistical Methods Group: The Cochrane Collaboration's tool for assessing risk of bias in randomised trials. BMJ 343: d5928, 2011. PMID: 22008217. DOI: 10.1136/bmj.d5928

56 National Toxicology Program's Office of Health Assessment and Translation (OHAT) Risk of Bias Rating Tool for Human and Animal Studies. Available at: https://ntp.niehs.nih.gov/ whatwestudy/assessments/noncancer/riskbias/index.html [Last accessed on June 29th, 2021]

57 Hirsch C and Schildknecht S: In vitro research reproducibility: Keeping up high standards. Front Pharmacol 10: 1484, 2019. PMID: 31920667. DOI: 10.3389/fphar.2019.01484

58 Guyatt G, Oxman AD, Akl EA, Kunz R, Vist G, Brozek J, Norris S, Falck-Ytter Y, Glasziou P, DeBeer H, Jaeschke R, Rind D, Meerpohl J, Dahm $P$ and Schünemann HJ: GRADE guidelines: 1. Introduction-GRADE evidence profiles and summary of findings tables. J Clin Epidemiol 64(4): 383-394, 2011. PMID: 21195583. DOI: 10.1016/j.jclinepi.2010.04.026

59 Whiting PF, Rutjes AW, Westwood ME, Mallett S, Deeks JJ, Reitsma JB, Leeflang MM, Sterne JA, Bossuyt PM and QUADAS-2 Group: QUADAS-2: a revised tool for the quality assessment of diagnostic accuracy studies. Ann Intern Med 155(8): 529-536, 2011. PMID: 22007046. DOI: 10.7326/00034819-155-8-201110180-00009

60 Wells GA, Shea B, O'Connell D, Peterson J, Welch V, Losos M and Tugwell P: The Newcastle-Ottawa Scale (NOS) for assessing the quality of nonrandomised studies in meta-analyses. Available at: http://www.ohri.ca/programs/clinical_epidemiology/nosgen.pdf [Last accessed on November 2nd, 2020]

61 Schneider K, Schwarz M, Burkholder I, Kopp-Schneider A, Edler L, Kinsner-Ovaskainen A, Hartung T and Hoffmann S: "ToxRTool", a new tool to assess the reliability of toxicological data. Toxicol Lett 189(2): 138-144, 2009. PMID: 19477248. DOI: $10.1016 /$ j.toxlet.2009.05.013

62 Golbach LA, Portelli LA, Savelkoul HF, Terwel SR, Kuster N, de Vries RB and Verburg-van Kemenade BM: Calcium homeostasis and low-frequency magnetic and electric field exposure: A systematic review and meta-analysis of in vitro studies. Environ Int 92-93: 695-706, 2016. PMID: 26872872. DOI: $10.1016 /$ j.envint 2016.01 .014

63 AlShwaimi E, Bogari D, Ajaj R, Al-Shahrani S, Almas K and Majeed A: In vitro antimicrobial effectiveness of root canal sealers against enterococcus faecalis: a systematic review. J Endod 42(11): 1588-1597, 2016. PMID: 27623499. DOI: $10.1016 /$ j.joen .2016 .08 .001

64 Viswanathan M and Berkman ND: Development of the RTI item bank on risk of bias and precision of observational studies. J Clin Epidemiol 65(2): 163-178, 2012. PMID: 21959223. DOI: 10.1016/j.jclinepi.2011.05.008

65 von Elm E, Altman DG, Egger M, Pocock SJ, Gøtzsche PC, Vandenbroucke JP and STROBE Initiative: The Strengthening the Reporting of Observational Studies in Epidemiology (STROBE) Statement: guidelines for reporting observational studies. Int J Surg 12(12): 1495-1499, 2014. PMID: 25046131. DOI: 10.1016/j.ijsu.2014.07.013 
66 Suarez-Almazor ME, Belseck E, Homik J, Dorgan M and Ramos-Remus C: Identifying clinical trials in the medical literature with electronic databases: MEDLINE alone is not enough. Control Clin Trials 21(5): 476-487, 2000. PMID: 11018564. DOI: $10.1016 / \mathrm{s} 0197-2456(00) 00067-2$

67 Harsono D, Finelt N, Castano EB, Tonnesen MG and Clark RA: Curcumin myths or wonders? A systematic analysis of in vitro studies. Wound Repair Regen 21(2): 335-336, 2013. PMID: 23464635. DOI: $10.1111 /$ wrr. 12019

68 Rahman NA, Rasil ANHM, Meyding-Lamade U, Craemer EM, Diah S, Tuah AA and Muharram SH: Immortalized endothelial cell lines for in vitro blood-brain barrier models: A systematic review. Brain Res 1642: 532-545, 2016. PMID: 27086967. DOI: 10.1016/j.brainres.2016.04.024

69 O’Dea RE, Lagisz M, Jennions MD, Koricheva J, Noble DWA, Parker TH, Gurevitch J, Page MJ, Stewart G, Moher D and Nakagawa S: Preferred reporting items for systematic reviews and meta-analyses in ecology and evolutionary biology: a PRISMA extension. Biol Rev Camb Philos Soc 96(5): 16951722, 2021. PMID: 33960637. DOI: 10.1111/brv.12721
70 Page MJ, McKenzie JE, Bossuyt PM, Boutron I, Hoffmann TC, Mulrow CD, Shamseer L, Tetzlaff JM, Akl EA, Brennan SE, Chou R, Glanville J, Grimshaw JM, Hróbjartsson A, Lalu MM, Li T, Loder EW, Mayo-Wilson E, McDonald S, McGuinness LA, Stewart LA, Thomas J, Tricco AC, Welch VA, Whiting P and Moher D: The PRISMA 2020 statement: an updated guideline for reporting systematic reviews. BMJ 372: n71, 2021. PMID: 33782057. DOI: 10.1136/bmj.n71
Received September 1, 2021

Revised September 23, 2021

Accepted September 28, 2021 